\title{
On the Scientific Status of Economic Policy: A Tale of Alternative Paradigms
}

\author{
Giorgio Fagiolo* \\ January 2008 \\ First draft, Please do not quote
}

Andrea Roventini ${ }^{\dagger}$

\begin{abstract}
In the last years, a number of contributions has argued that monetary - and, more generally, economic - policy is finally becoming more of a science. According to these authors, policy rules implemented by central banks are nowadays well supported by a theoretical framework (the New Neoclassical Synthesis) upon which a general consensus has emerged in the economic profession. In other words, scientific discussion on economic policy seems to be ultimately confined to either fine-tuning this "consensus" model, or assessing the extent to which elements of art still exist in the conduct of monetary policy. In this paper, we present a substantially opposite view, rooted in a critical discussion of the theoretical, empirical and political-economy pitfalls of the neoclassical approach to policy analysis. Our discussion indicates that we are still far from building a science of economic policy. We suggest that a more fruitful research avenue to pursue is to explore alternative theoretical paradigms, which can escape the strong theoretical requirements of neoclassical models (e.g., equilibrium, rationality, etc.). We briefly introduce one of the most successful alternative research projects - known in the literature as agent-based computational economics (ACE) - and we present the way it has been applied to policy analysis issues. We conclude by discussing the methodological status of ACE, as well as the (many) problems it raises.
\end{abstract}

Keywords: Economic Policy, Monetary Policy, New Neoclassical Synthesis, New Keynesian Models, DSGE Models, Agent-Based Computational Economics, Agent-Based Models.

JEL Classification: B41, B50, E32, E52.

\footnotetext{
${ }^{*}$ Corresponding Author. Sant'Anna School of Advanced Studies, Pisa, Italy. Mail address: Sant'Anna School of Advanced Studies, Piazza Martiri della Libertà 33, I-56127 Pisa, Italy. Tel: +39-050-883282. Fax: +39-050883344. Email: giorgio.fagiolo@sssup.it

${ }^{\dagger}$ University of Modena and Reggio Emilia, Italy and Sant'Anna School of Advanced Studies, Pisa, Italy. Mail address: Università di Modena e Reggio Emilia, Facoltà di Scienze della Comunicazione e dell'Economia, Dipartimento di Scienze Sociali, Cognitive e Quantitative, via A. Allegri 9, I-42100 Reggio Emilia, Italy. Tel: +39-0522-523000. Fax: +39-0522-523205. Email: aroventini@sssup.it
} 


\section{Introduction}

In the last years, a number of contributions has argued that monetary - and, more generally, economic - policy is finally becoming more of a science (Mishkin, 2007; Galí and Gertler, 2007; Goodfriend, 2007; Taylor, 2007). Nowadays, these authors maintain, both the academic world and central banks have reached an overall consensus not only on the contingency rules to implement in alternative situations, but also on the fact that "the practice of monetary policy reflects the application of a core set of scientific principles" (Mishkin, 2007, p.1). These scientific principles, in turn, derive from the so-called New Neoclassical Synthesis or the New Keynesian model of monetary policy (Goodfriend, 2007), whose highly-sophisticated, brand-new reincarnation is based upon the Dynamic Stochastic General Equilibrium (DSGE) model (Woodford, 2003; Galí and Gertler, 2007).

What is more, the available toolbox of economic policy rules is deemed to work exceptionally well not only for normative purposes, but also for descriptive ones. For example, Taylor (2007) argues that "while monetary policy rules cannot, of course, explain all of economics, they can explain a great deal" (p.1) and also that "although the theory was originally designed for normative reasons, it has turned out to have positive implications which validate it scientifically" (abstract).

The resulting picture is an extremely reassuring, but also somewhat scaring, one. For it envisages, for the next future, a situation where no matter the country under consideration and the historic time a handful of simple, scientifically-sound, contingency rules will always be at disposal of central banks and other economic decision makers. They will just need to program a powerful-enough computer that, conditional to the state of the economy, will automatically and carefully design the optimal policy to implement. The value added of economists and politicians will then look like increasingly similar to that of an airliner pilot: the theoretical model, with its technical sophistication, will do almost all the job, whereas the role of the policy maker will soon become negligible. Scientific discussions on economic policy seem therefore to be ultimately confined to either fine-tuning the "consensus" model, or assessing the extent to which elements of art (appropriable by the policy maker) still exist in the conduct of monetary policy (Mishkin, 2007).

Strangely enough, all that resembles very closely two famous statements made, respectively, by Francis Fukuyama (1992) about an alleged "end of history", and by many physicists in the recent debate on a purported "end of physics" (see, e.g., Lindley, 1994). Unfortunately to those who promoted and supported them, both positions have been proven to be substantially wrong by subsequent developments.

In this paper, we argue that this is likely to happen also with the view on economic policy expressed by those supporting the "New Neoclassical Synthesis" approach. Our argumentation is based on two related considerations.

First, we claim that policy rules actually implemented by central banks and other institutions are seldom backed up by sound theoretical models. As recently discussed at length in Aghion and Howitt (2007) in the context of growth policies, the most frequent situation faced by an advisor asked to deliver policy recommendations is one where standard textbook recipes turn out to be useless. A case-by-case approach, where one relies primarily on instincts and common 
sense, is instead to be preferred (Aghion and Howitt, 2007, p.2). As far as monetary and fiscal policies are concerned, things are not that different. As Section 2 shows, the state-of-the-art theoretical apparatus employed to provide scientific support to policy rules (i.e., DSGE-based models) turns out to be a juxtaposition of separate modules, namely a real business cycle backbone, a monopolistic competition framework, nominal imperfections and a monetary policy rule. Therefore, it hardly represents a unified (and unifying) framework. The set of policy rules that is deemed to uphold may have been derived separately by different single modules or simply as rules of thumb. In this perspective, the elements of art still existing in the job of policy maker are far from becoming negligible.

Second, the DSGE policy apparatus is plagued by a long list of serious problems. These include theoretical issues (i.e., having to do with formal inconsistencies of the model - given its assumptions), empirical difficulties (i.e., related to empirical validation of DSGE models) and political-economy problems (i.e., concerning the absence of any justification for the often unrealistic and over-simplifying assumptions used to derive policy implications).

As the discussion of Section 2 indicates, this should prevent any open-minded economist from unfalteringly declaring that DSGE models are the end point of research on economic policy. Rather, we suggest that a more fruitful research avenue to pursue is to explore alternative theoretical paradigms, which can escape the strong theoretical requirements of the New Neoclassical Synthesis (e.g., equilibrium, rationality, etc.). Among those alternative paradigms, one of the most successful research project is the one known in the literature as agent-based computational economics (ACE). In a nutshell, ACE is the computational study of economies thought as complex evolving systems (Tesfatsion, 2006). Bounded rationality, endogenous out-of-equilibrium dynamics, direct interactions are some of the keywords defining this approach (see Section 3 for more details). Due to the extreme flexibility of the set of assumptions regarding agent behaviors and interactions, ACE models (often called agent-based models, ABMs) represent an exceptional laboratory to perform policy exercises and policy design. Despite this approach is still in its infancy (at least as compared to the neoclassical one), many policy applications have been already devised and explored. Of course, also ACE models are affected by methodological problems. The most important ones concern empirical validation, over-parametrization, estimation and calibration. Nevertheless, the success of ACE models in delivering policy implications while simultaneously explaining the observed stylized facts surely prompts for further research in this field.

The rest of the paper is organized as follows. Section 2 surveys the approach to policy of the New Neoclassical Synthesis, and it discusses its many theoretical and empirical difficulties. In Section 3 we instead introduce the ACE paradigm and we briefly review some policy applications in this field. Section 4 concludes by telegraphically accounting for some methodological issues related to policy in ACE models and the ensuing research avenues that these problems open up.

\section{Policy in the Neoclassical Framework}

Let us begin by presenting how policy analysis is usually carried out in a neoclassical framework. More precisely, we restrict our attention to macroeconomics, in particular to short-run business cycle models. Our choice is motivated by two reasons. First, in business cycle and monetary 
economics there is now a wide consensus among neoclassical economists on the model and on the methodology to employ to perform policy analysis exercises. Second, business cycle and monetary economics are probably the fields of research where the neoclassical paradigm has developed the most sophisticated and rigorous models and techniques to assess the impact of different policies on the economic welfare of agents ${ }^{1}$. In the next sections, we first present the neoclassical model and methodology. We then consider the major weaknesses and problems of the neoclassical approach to perform policy analysis.

\subsection{The Dynamic Stochastic General Equilibrium Model}

The clash between the two competing business cycle theories - the Real Business Cycle (RBC) perspective (see e.g. King and Rebelo, 1999) and the New Keynesian paradigm (cf. Mankiw and Romer, 1991) - ended in the last decade with the development of a New Neoclassical Synthesis $(\mathrm{NNS})^{2}$. In a nutshell, the canonical model employed by the NNS paradigm is basically a RBC dynamic stochastic general equilibrium (DSGE) model with monopolistic competition, nominal imperfections and a monetary policy rule (see Woodford, 2003; Galí and Gertler, 2007; Galí, 2007, for a more detailed exposition of the NNS approach).

In line with the RBC tradition, the starting point of the new vintage models is a stochastic version of the standard neoclassical growth model with variable labor supply: the economy is populated by an infinitely-lived representative household, who maximizes its utility under an intertemporal budget constraint, and by a large number of firms, whose homogenous production technology is hit by exogenous shocks. The New Keynesian flavor of the model stems from three ingredients: money, monopolistic competition and sticky prices. Money has usually only the function of unit of account and its short-run non-neutrality is guaranteed by the nominal rigidities introduced by sticky prices. As a consequence, the central bank can influence the real economic activity in the short run by manipulating the interest rate. The RBC scaffold of the model allows one to compute the "natural" level of output and of the real interest rate, that is the equilibrium values of the two variables under perfectly flexible prices. The "natural" output and interest rate constitute a benchmark for monetary policy: the central bank cannot persistently push the output and the interest rate away from their "natural" values without creating inflation or deflation. Note that the assumption of imperfect competition (and of other real rigidities) implies that the "natural" level of output is not socially efficient.

Analytically, the NNS model can be represented by three equations ${ }^{3}$ : the expectationaugmented IS equation, the New Keynesian Phillips (NKP) curve, and a monetary policy rule. The expectation-augmented IS equation constitutes the aggregate-demand building block of the NNS model. Assuming perfect capital markets and taking a log-linear approximation around the steady state, one can derive the IS equation from the goods market-clearing condition and

\footnotetext{
${ }^{1}$ For example, neoclassical economics is still far from developing a common model where different policy issues related to economic growth may be evaluated (an alternative view is discussed in Aghion and Howitt (2007)). For these reasons we chose not to consider here long-run macro-economic issues.

${ }^{2}$ This term was first introduced by Goodfriend and King (1997). Woodford (2003) labeled the approach as "Neo Wicksellian". As stated by Galí and Gertler (2007) the term "New Keynesian" is the most used, even if earlier New Keynesian models were very different from the ones of the New Neoclassical Synthesis.

${ }^{3}$ For a formal derivation of the NNS model see Goodfriend and King (1997); Clarida, Galí, and Gertler (1999); Woodford (2003); Galí (2007).
} 
the Euler equation of the representative household:

$$
\tilde{y}_{t}=E_{t} \tilde{y}_{t+1}-\sigma\left(i_{t}-E_{t} \pi_{t+1}-r_{t}^{n}\right)
$$

where $\tilde{y}$ is the output gap (i.e., the percentage gap between real output and its "natural" level), $\sigma$ is the intertemporal elasticity of substitution of consumption, $i$ is the nominal interest rate, $\pi$ is inflation, $r^{n}$ is the "natural" interest rate and $E_{t}$ stands for the expectation operator taken at time $t$. Note that in line with the traditional IS-LM model, the IS equation postulates a negative relation between the output gap and the interest rate gap.

The aggregate-supply building block of the NNS model boils down to a New Keynesian Phillips curve. Starting from the Dixit and Stiglitz (1977) model of monopolistic competition and the Calvo (1983) model of staggered prices (with constant probability of price adjustment), one gets that in any given period firms allowed to adjust prices fix them as a weighted average of the current and expected future nominal marginal cost. The NKS curve can be obtained by combining the log-linear approximation of the optimal price-setting choice, the price index and the labor-market equilibrium:

$$
\pi_{t}=\kappa \tilde{y}_{t}+\beta E_{t} \pi_{t+1}+u_{t},
$$

where $\beta$ is the subjective discount factor of the representative household and $\kappa$ depends both on the elasticity of marginal cost with respect to output and on the sensitivity of price adjustment to marginal cost fluctuations (i.e., frequency of price adjustment and real rigidities induced by price complementarities). The term $u$ is usually considered a "cost-push shock": it captures the fact that the natural level of output may not coincide with the socially efficient one for the presence of real imperfections such as monopolistic competition, labor market rigidities, etc. The presence of $u$ implies that inflation does not depend only on the presence of a positive output gap, but also on other factors affecting firms' real marginal costs (the output gap appears in equation 2 because in the underlying model there is a positive relation between $\tilde{y}$ and the $\log$ deviation of real marginal cost from its natural level).

The model just sketched leads to a system of two difference equations (cf. eqs. 1 and 2) and three unknowns: the output gap, inflation, and the nominal interest rate. In order to solve the system, one has to append a rule to determine the nominal interest rate. This is the role reserved to monetary policy. The choice of a monetary policy rule is usually carried out adopting a welfare criterion: taking a second-order Taylor series approximation of the utility of the representative household, one can derive a welfare loss function for the central bank that is quadratic in inflation and in deviations of output from its socially efficient level (see Rotemberg and Woodford, 1999; Woodford, 2003). Even if optimal monetary policy rules could be in principle derived (see e.g. Giannoni and Woodford, 2002a,b), the NNS model is often closed with "simple" rules such as the Taylor (1993) rule (more on that in Section 2.2.3):

$$
i_{t}^{\tau}=r_{t}^{n}+\phi_{\pi} \pi_{t}+\phi_{y} \tilde{y}_{t}
$$

where $i^{\tau}$ is the interest rate target of the central bank, $\phi_{y}>0$ and $\phi_{\pi}>1$. Before performing policy exercises with the model, one should assess its empirical performance and calibrate its parameters. 
When taken to the data (see e.g. Christiano, Eichenbaum, and Evans, 2005; Smets and Wouters, 2003), canonical DSGE models like the one presented above are usually expanded to account for investment dynamics. Moreover, different type of shocks are added to both the IS equation, assuming for instance government spending and private consumption disturbances, and the monetary policy rule. Finally, standard DSGE models have also to be modified because they are too much forward-looking to match the econometric evidence on the co-movements of nominal and real variables (e.g., impulse-response functions of output and inflation as to a monetary policy shock). Hence, in order to reproduce the inertia and persistency found in real data, the DSGE models are extended introducing a great deal of "frictions" - often not justified on the theoretical ground - such as predetermined price and spending decisions, indexation of prices and wages to past inflation, sticky wages, habit formation in preferences for consumption, adjustment costs in investment, variable capital utilization, etc..

From an econometric perspective, the equations 1-3 of the DSGE model are naturally represented as a vector auto-regression (VAR) model. The estimation of the resulting econometric model is usually carried out either with a limited information approach or by full-information likelihood-based methods.

Limited information approach. The strategy of the limited information approach to estimate and evaluate DSGE models is usually the following (e.g., Rotemberg and Woodford, 1999; Christiano, Eichenbaum, and Evans, 2005):

1. Specify the monetary policy rule and the laws of motion for the shocks.

2. Split the parameters in two sets and calibrate the parameters in the first set providing some theoretical or empirical justifications for the chosen values.

3. Fix the timing of the endogenous variables in order to allow the interest rate to respond to contemporaneous output and inflation, while the latter variables are only affected by lagged interest rate. Under this assumption one can estimate via OLS the coefficients of the monetary policy rule and the impulse-response functions of the three variables to a monetary policy shock.

4. Recover the second set of parameters by minimizing the distance between the modelgenerated and empirical impulse-response functions.

5. Finally, given the structural parameter values and the VAR, identify the other structural shocks by imposing, if necessary, additional restrictions.

The empirical performance of the model is then measured by comparing the impulse-response functions generated by the model with the empirical ones.

Full information approach. The full information approach was initially discarded to estimate DSGE models because maximum likelihood methods deliver implausible estimates. However, with the introduction of Bayesian techniques, the full information approach regained popularity and it is now commonly employed (see e.g. Smets and Wouters, 2003). Bayesian estimation is carried out according to the following steps: 
1. Place some restrictions on the shocks in order to allow later identification.

2. Employ the Kalman filter to compute the likelihood function of the observed time series.

3. Form the prior distribution of the parameters by choosing their initial values through calibration, preliminary exploratory exercises, and/or to get some desired statistical properties.

4. Combine the likelihood function with the prior distribution of the parameters to obtain the posterior density, which is then used to compute parameter estimates.

One can then assess the empirical performance of the estimated DSGE model comparing its marginal likelihood with the one of standard VAR models and the model-generated crosscovariances vis-á-vis the empirical ones.

Once one has recovered the parameters of the model by estimation or calibration and has identified the structural shocks, policy-analysis exercises can finally be carried out. More specifically, after having derived the welfare loss function, one can assess the performance of the subset of "simple" policy rules that guarantee the existence of a determinate equilibrium or the more appropriate parametrization within the class of optimal monetary policy rules. This can be done via simulation, by buffeting the DSGE model with different structural shocks and computing the resulting variance of inflation and the output gap and the associated welfare losses of the different monetary policy rules and parameterizations employed (see e.g. Rotemberg and Woodford, 1999; Galí and Gertler, 2007). In practice, assuming that the DSGE model is the "true" data generating process of the available time series, one is evaluating how the economy portrayed by the model would react to the same structural shocks observed in the past if the monetary policy followed by the central bank were different.

\subsection{Policy with DSGE Models: A Safe Exercise?}

DSGE models are plagued by at least three classes of problems which could potentially undermine the usefulness of performing policy-analysis exercises in such a framework. More specifically, DSGE models are subject to theoretical, empirical, and political-economy problems that we shall discuss in the next sections.

\subsubsection{Theoretical Issues}

From a theoretical perspective, DSGE models are general equilibrium models (GE) rooted in the Arrow-Debreu tradition with some minor non-Walrasian features (e.g., sticky prices). Hence, they share with traditional GE models their same problems and weaknesses. Even if there is a vast and widely-known literature within the neoclassical paradigm dealing with the theoretical issues affecting GE models (see e.g. Kirman, 1989), we briefly recall what are the major problems at hand.

To begin with, sufficient conditions allowing for the existence of a general equilibrium do not ensure neither its uniqueness nor its stability. In addition, the well-known results obtained by Sonnenschein (1972), Debreu (1974) and Mantel (1974) show that one can never restrict agents' 
characteristics (e.g., endowments, preferences, etc.) in such a way to attain uniqueness and stability. What is more, Kirman and Koch (1986) show that even if agents are almost identical (i.e., same preferences and almost identical endowments), uniqueness and stability can hardly be recovered.

In this framework, the strategy followed by neoclassical economists to get stable and unique equilibria is to introduce a representative agent (RA). If the choices of heterogeneous agents collapse to the ones of a representative individual, one can circumvent all the problems stemming from aggregation and provide GE macroeconomic models with rigorous Walrasian microfoundations grounded on rationality and constrained optimization. However, the RA assumption is far from being innocent: there are (at least) four reasons for which it cannot be defended (Kirman, 1992). First, individual rationality does not imply aggregate rationality: one cannot provide any formal justification to support the assumption that at the macro level agents behave as a maximizing individual. Second, even if one forgets the previous point and uses the RA fiction to provide micro-foundations to macroeconomic models, one cannot safely perform policy analyses with such models, because the reactions of the representative agent to shocks or parameter changes may not coincide with the aggregate reactions of the represented agents. Third, even if the first two problems are solved, there may be cases where given two situations $a$ and $b$, the representative agent prefers $a$, whereas all the represented individuals prefer $b$.

Finally, the RA assumption introduces additional difficulties at the empirical level, because whenever one tests a proposition delivered by a RA model, one is also jointly testing the RA hypothesis. Hence, the rejection of the latter hypothesis may show up in the rejection of the model proposition that is being tested. This last point is well corroborated by the works of Forni and Lippi $(1997,1999)$, who show that basic properties of linear dynamic micro-economic models are not preserved by aggregation if agents are heterogeneous. To cite some examples, micro-economic co-integration does not lead to macroeconomic co-integration, Granger-causality may not appear at the micro level, but it may emerge at the macro level, aggregation of static micro-equations may produce dynamic macro-equations. As a consequence, one can safely test the macroeconomic implications of micro-economic theories only if careful and explicit modeling of agents' heterogeneity is carried out.

The fact that solving DSGE models leads to a system of difference equations may potentially add another problem to those discussed above. More specifically, one has to check whether the solution of the system of equilibrium conditions of a DSGE model exists and is determinate. If the exogenous shocks and the fluctuations generated by the monetary policy rule are "small", and the "Taylor principle" holds (i.e., $\phi_{\pi}>1$, see eq. 3), one can prove existence and local determinacy of the rational expectation equilibrium of the DSGE model presented in Section 2.1 (Woodford, 2003) ${ }^{4}$. This result allows one to perform comparative-statics exercises in presence of "small" shocks or parameter changes and to safely employ log-linear approximations around the steady state. Unfortunately, the existence of a local determinate equilibrium does not rule out the possibility of multiple equilibria at the global level (see e.g. Schmitt-Grohé and Uribe, 2000; Benhabib, Schmitt-Grohé, and Uribe, 2001).

\footnotetext{
${ }^{4}$ Of course, also other monetary policy rules different from the Taylor rule (cf. eq. 3) can lead to a local determinate rational-expectation equilibrium.
} 


\subsubsection{Empirical Issues}

The second stream of problems is related to the empirical validation of DSGE models. As remarked by Canova (2007), estimation and testing of DSGE models are performed assuming that they represent the true data generating process (DGP) of the observed data. This implies that the ensuing inference and policy experiments are valid only if the DSGE model mimics the unknown DGP of the data.

As mentioned in Section 2.1, DSGE models can be represented as a VAR of the form:

$$
A_{0}(\phi) x_{t}=H_{1}(\phi) x_{t-1}+H_{2}(\phi) E_{t},
$$

where $x$ are both endogenous and exogenous variables, $\phi$ is the vector of the parameters of the model and $E$ contains the errors. If the matrix $A_{0}$ is invertible, one can obtain a reduced-form VAR representation of the DSGE model.

Following Fukac and Pagan (2006), the econometric performance of DSGE models can be assessed along the identification, estimation and evaluation dimensions. Before going in depth with this type of analysis, two preliminary potential sources of problems must be discussed. First, the number of endogenous variables contemplated by DSGE models is usually larger than the number of structural shocks. This problem may lead to system singularity and it is typically solved by adding measurement errors. Second, $H_{1}$ and $H_{2}$ are reduced rank matrixes. This problem is circumvented by integrating variables out of the VAR (eq. 4) as long as $H_{1}$ and $H_{2}$ become invertible. This process leads to a VARMA representation of the DSGE model. This is not an innocent transformation for two reasons: i) if the moving average component is not invertible, the DSGE model cannot have a VAR representation; ii) even if the VAR representation of the DSGE model exists, it may require an infinite number of lags (more on that in FernandezVillaverde, Rubio-Ramirez, and Sargent, 2005; Ravenna, 2007; Alessi, Barigozzi, and Capasso, 2007).

Identification. Given the large number of non-linearities present in the structural parameters $(\theta)$, DSGE models are hard to identify (Canova, 2007). This leads to a large number of identification problems, which can affect the parameter space either at the local or at the global level. A taxonomy of the most relevant identification problems can be found in Canova and Sala $(2005)^{5}$. To sum them up: i) different DSGE models with different economic and policy implications could be observationally equivalent (i.e., they produce indistinguishable aggregate decision rules); ii) some DSGE models may be plagued by under or partial identification of their parameters (i.e., some parameters are not present in the aggregate decision rules or are present with a peculiar functional form); iii) some DSGE may be exposed to weak identification problems (i.e., the mapping between the coefficients of the aggregate decision rules and the structural parameters may be characterized by little curvature or by asymmetries), which could not even be solved by increasing the sample size.

Identification problems lead to biased estimates of some structural parameters and do not allow to rightly evaluate the significance of the estimated parameters applying standard asymptotic theories. This opens a ridge between the real and the DSGE DGPs, depriving parame-

\footnotetext{
${ }^{5}$ See also Beyer and Farmer (2004).
} 
ter estimates of any economic meaning and making policy analysis exercises useless (Canova, 2007). In most of the cases, identification problems can only be mitigated by appropriately re-parameterizing the model ${ }^{6}$.

Estimation. The identification problems discussed above partly affect the estimation of DGSE models. DSGE models are very hard to estimate by standard maximum likelihood (ML) methods, because ML estimator delivers biased and inconsistent results if the system is not a satisfying representation of the data. This turns out to be the case for DSGE models (see the evaluation section) and it helps to explain why ML estimates usually attain absurd values with no economic meaning and/or they are incompatible with a unique stable solution of the underlying DSGE model.

A strategy commonly employed when the DSGE model is estimated following the limitedinformation approach (cf. Section 2.1) consists in calibrating the parameters hard to identify and then estimating the others. Given the identification problems listed above, Canova (2007) argues that this strategy works only if the calibrated parameters are set to their "true" values. If this is not the case, estimation does not deliver correct results that can be used to address economic and policy questions (see also Canova and Sala, 2005).

As we mentioned in Section 2.1, Bayesian methods are now commonly employed to estimate DSGE models. They apparently solve the problems of estimation (and identification) by adding a $(\log )$ prior function to the $(\log )$ likelihood function in order to increase the curvature of the latter and obtain a smoother function. However, this choice is not harmless: if the likelihood function is flat - and thus conveys little information about the structural parameters - the shape of the posterior distribution resembles the one of the prior, reducing estimation to a more sophisticated calibration procedure carried out on an interval instead on a point (see Canova, 2007; Fukac and Pagan, 2006). Unfortunately, the likelihood functions produced by most DSGE models are quite flat (see e.g. the exercises performed by Fukac and Pagan, 2006). In this case, informal calibration is a more honest and internally consistent strategy to set up a model for policy analysis experiments (Canova, 2007).

All the estimation problems described above stem also from the fact that DSGE models are not conceived to simplify the estimation of their parameters (Canova, 2007). As a consequence DSGE models put too much stress upon the data, using for instance more unobservable that observable variables (Fukac and Pagan, 2006). This requires strong assumptions about the variances in order to get identification and to employ Kalman filter to obtain the likelihood function. The likelihood functions produced by the Kalman filter are correct only if observations are Gaussian, but macroeconomic time series are typically not normally-distributed (Fagiolo, Napoletano, and Roventini, 2007).

Evaluation. Evaluating DSGE models means assessing their capability to reproduce as many empirical stylized facts as possible. For instance, following Fukac and Pagan (2006), one can check: i) whether variables with deterministic trend cotrend; ii) whether I(1) variables cointegrate and the resulting co-integrating vectors are those predicted by the model; iii) the

\footnotetext{
${ }^{6}$ Fukac and Pagan (2006) also argue that identification problems are usually partly mitigated by arbitrarily assuming serially correlated shocks.
} 
consistency (with respect to data) of the dynamic responses (e.g., autocorrelation, bivariate correlations); iv) the consistency of the covariance matrix of the reduced form errors with the one found in the data; v) the discrepancies between the time series generated by the model and real-world ones.

Fukac and Pagan (2006) perform such exercises on a popular DSGE model. First, they find that co-trending behaviors cannot be assessed because data are demeaned (a practice commonly followed by DSGE modelers). However, the computation of the technology growth rates compatible with the observed output growth rates shows that the possibility of technical regress is very high. Second, there are no co-integrating vectors, because output is the only I(1) variable. Third, the model is not able to successfully reproduce the mean, standard deviations, autocorrelations, bivariate correlations observed in real data. In addition, the DSGE model predicts the constancy of some "great" ratios (in line with the presence of a steady state of the economy), but this is not confirmed by real data. Fourth, many off-diagonal correlations implied by the covariance matrix of the errors are significantly different from zero, contradicting the DSGE model assumption of uncorrelated shocks. Finally, the tracking performance of the model depends heavily on the assumed high serial correlation of the shocks.

The results just described seem to support Favero (2007) in claiming that modern DSGE models are exposed to the same criticisms advanced against the old-fashioned macroeconometric models belonging to the Cowles Commission tradition: they pay too much attention to the identification of the structural model (with all the problems described above) without testing the potential misspecification of the underlying statistical model". In DSGE models, "restrictions are made fuzzy by imposing a distribution on them and then the relevant question becomes what is the amount of uncertainty that we have to add to model based restrictions in order to make them compatible not with the data but with a model-derived unrestricted VAR representation of the data" (Favero, 2007, p. 29). There are many signals of the potential misspecification of the statistical model delivered by DSGE models: the presence of many persistent shocks, the fact that theory-free VAR models of monetary policy need to include additional variables such as commodity price index to match the data, the absurd estimates produced by standard maximum likelihood estimation, etc. (Fukac and Pagan, 2006; Favero, 2007). If the statistical model is misspecified, policy analysis exercises loose significance, because they are carried out in a "virtual" world whose DGP is different from the one underlying observed time-series data.

\subsubsection{Political-Economy Issues}

Given the theoretical problems and the puny empirical performance of DSGE models, one cannot accept the principles of the positive economics approach summarized by the "as if" argument of Milton Friedman (1953). The assumptions of DSGE models can no longer be defended invoking arguments such as parsimonious modeling or matching the data. This opens a Pandora's box, forcing us to consider how policy-analysis exercises performed with DSGE models are influenced and constrained by the legion of underlying assumptions.

\footnotetext{
${ }^{7}$ On the contrary, the LSE-Copenhagen school follows a macroeconometric modeling philosophy orthogonal to the one followed by DSGE modelers. Scholars of the LSE-Copenhagen approach have concentrated their efforts on improving the statistical model in order to structure data with an identified co-integrated VAR that could then be used to produce stylized facts for theoretical models (Juselius and Franchi, 2007).
} 
DSGE models presume a very peculiar and un-realistic framework, where agents endowed with rational expectations take rational decisions by solving dynamic programming problems. This implies that: i) agents perfectly know the model of the economy; ii) agents are able to understand and solve every problem they face without making any mistakes; iii) agents know that all other agents behave according to the first two points. In practice, agents are endowed with a sort of "olympic" rationality and have free access to the whole information set. Moreover, the implicit presence of a Walrasian auctioneer, which sets prices before exchanges take place, coupled with the representative-agent assumption, rule out almost by definition the possibility of interactions carried out by heterogeneous individuals. Besides being responsible for the problems analyzed in Sections 2.2.1 and 2.2.2, these assumptions strongly reduce the realism of DSGE models. This is not a minor issue when one has to perform policy analyses.

More generally, within the Neoclassical-DSGE paradigm there is a sort of internal contradiction. On the one hand, strong assumptions such as rational expectations, perfect information, complete financial markets are introduced ex-ante to provide a rigorous and formal mathematical treatment of the problems and to allow for policy recommendations. On the other hand, many imperfections (e.g., sticky prices, rule-of-thumb consumers) are introduced ex-post without any theoretical justification only to allow DSGE model to match the data ${ }^{8}$. Adopting less stringent assumptions may contribute to jointly solve many empirical puzzles without introducing an army of ad-hoc imperfections.

There are a couple of other internal inconsistencies which could potentially undermine the reliability of the policy prescriptions developed following the DSGE approach. The first one is related to the role of money. DSGE models are specifically designed to perform monetary policy analyses, but money is almost never explicitly modeled. This choice is usually justified by: i) assuming that money is not an asset and it has only the function of unit of account (cf. Section $2.1)$; ii) introducing money in the utility function of consumers with the caveat that transactions requiring money are sufficiently unimportant, and arguing that for "reasonable" calibrations, the enriched model delivers almost the same results of the standard DSGE model presented in Section 2.1 (Woodford, 2003, chapter 2). Of course, the unimportance of transactions requiring money, the calibration reasonability and the quantitative discrepancies between standard and money-augmented DSGE models is debatable and subject to the judgement of policymakers.

The second potential inconsistency concerns how business cycles arise in the DSGE framework. DSGE models con be employed to assess the impact of different monetary policies because they are genuine business cycle models. However, the theory of business cycles embedded in DSGE models is exogenous: the economy rests in the steady state unless it is hit by a stream of exogenous stochastic shocks. As a consequence, DSGE models do not explain business cycles, preferring instead to generate them with a sort of deus-ex-machina mechanism. This could explain why DSGE models are not able to match many business cycle stylized facts or have to assume serially correlated shocks to produce fluctuations resembling the ones observed in reality (cf. Zarnowitz, 1985, 1997; Cogley and Nason, 1993; Fukac and Pagan, 2006). How policymakers can assess the impact of countercyclical policies in models not explaining business cycles is an open issue.

\footnotetext{
${ }^{8}$ Citing a very provocative sentence of a famous evolutionary economist, this way of theorizing is like claiming that biology stems from thermodynamics equilibrium with some imperfections.
} 
Moving to the normative side, one supposed advantage of the DSGE approach is the possibility to derive optimal policy rules. However, policymakers adopting optimal policy rules face certain costs - the strict assumptions at the root of DSGE models - but uncertain benefits. As argued by Galí (2007), optimal monetary policy rules cannot be used in practice, because they require the knowledge of the "true" model of the economy, the exact value of every parameter, and the real time value of every shocks. Moreover, Brock et al. (2007) show that when the "true" model of the economy and the appropriate loss function are not know, rule-of-thumb policy rules may perform better than optimal policy rules.

\subsection{Any Ways Out?}

Given the theoretical and empirical problems of DSGE models discussed above, the positive economics approach advocated by Milton Friedman would suggest to remove or change the plethora of underlying assumptions in order to improve the performance of the model.

This recommendation is reinforced by two related observations. First, the assumptions underlying DSGE models become a sort of strait jacket that preclude the model to be flexible enough to allow for generalizations and extensions. Second, the un-realism of these assumptions prevent policymakers to fully trust the policy prescriptions developed with DSGE models.

It is far from clear why within the mainstream DSGE paradigm there is a widespread conservative attitude with no significative attempts to substitute the "Holy Trinity" assumptions of rationality, greed and equilibrium (Colander, 2005) with more realistic ones. For instance, Akerlof (2007) argues that a broader definition of agents' preferences which take into account the presence of realistic norms can violate many neutrality results of neoclassical economics without recurring to imperfections. Moreover, introducing heterogeneous agents or substituting the rationality assumption with insights coming from behavioral economics could substantially change the working of DSGE models, "making monetary policy more of a science" (Mishkin, 2007).

In any case, if neoclassical economists truly enlist themselves among those advocating an instrumentalist approach to scientific research, they should agree that when models display estimation and validation (descriptive) problems such as those exhibited by DSGE ones, the only way out would be to modify the models' assumptions. A fortiori, this should be the recommendation that an instrumentalist researcher would provide if, in addition, the model, as happens in the DSGE case, would also display problems on the normative side.

This is exactly the research avenue that a growing number of scholars have been pursuing in the last two decades. Dissatisfied with standard macroeconomic, micro-founded, generalequilibrium-based neoclassical models like those discussed above, they have begun to devise an entirely new paradigm labeled as "Agent-Based Computational Economics" (ACE). The basic exercise ACE tries to perform is building models based on more realistic assumptions as far as agent behaviors and interactions are concerned, where more realistic here means rooted in empirical and experimental micro-economic evidence. For example, following the body of evidence provided by cognitive psychologists (see for example, among a vast literature, Kahneman and Tversky, 2000), the assumptions of perfect rationality and foresight are replaced with those of bounded rationality and adaptive behavior. Similarly, insights from network theory (e.g., 
Albert and Barabasi, 2002) and social interactions (e.g., Brock and Durlauf, 2001) suggest to move away from the unrealistic and oversimplifying assumptions concerning agents interactions typically employed in neoclassical models and allow for direct, non-trivial interaction patterns. Finally, the widespread evidence on persistent heterogeneity and turbulence characterizing markets and economies indicate to abandon crazy simplifications such as the representative agent assumption, as well as the presumption that economic systems are (and must be observed) in equilibrium, and to focus instead on out-of-equilibrium dynamics endogenously fueled by the interactions among heterogenous agents.

In other words, ACE can be defined as the computational study of economies thought as complex evolving systems (Tesfatsion, 2006). Notice that neoclassical economics, on the contrary, typically deals with economies conceived as simple, linear, homogeneous and stationary worlds. It should not come as a surprise that the class of models used by ACE to explore the properties of markets, industries and economies (called agent-based models, ABMs) are far more complicated - and harder to analyze - objects than their neoclassical counterparts. In the following Section we will therefore begin by outlying the basic building blocks of ABMs. Next, we will address the question how ABMs can be employed to deliver normative implications. Then, we will briefly review some examples of policy exercises in ABMs. Some final remarks about pro and cons of using ABMs for policy analysis will be left for the concluding section.

\section{Agent-Based Models and Economic Policy}

\subsection{Building Blocks of ABMs}

The last two decades have seen a rapid growth of agent-based modeling in economics. An exhaustive survey of this vast literature is of course beyond the scope of this work ${ }^{9}$. However, before proceeding, it is useful to introduce the main ten ingredients that tend to characterize economics $\mathrm{AB}$ models.

1. A bottom-up perspective. A satisfactory account of a decentralized economy is to be addressed using a bottom-up perspective. In other words, aggregate properties must be obtained as the macro outcome of a possibly unconstrained micro dynamics going on at the level basic entities (agents). This contrasts with the top-down nature of traditional neoclassical models, where the bottom level typically comprises a representative individual and is constrained by strong consistency requirements associated with equilibrium and hyper-rationality.

2. Heterogeneity. Agents are (or might be) heterogeneous in almost all their characteristics.

3. The evolving complex system (ECS) approach. Agents live in complex systems that evolve through time. Therefore, aggregate properties are thought to emerge out of repeated interactions among simple entities, rather than from the consistency requirements of rationality and equilibrium imposed by the modeler.

\footnotetext{
${ }^{9}$ This and the following subsections heavily draw from Pyka and Fagiolo (2007) and Fagiolo, Moneta, and Windrum (2007). See the references therein and Tesfatsion and Judd (2006) for further details.
} 
4. Non-linearity. The interactions that occur in AB models are inherently non-linear. Additionally, non-linear feedback loops exist between micro and macro levels.

5. Direct (endogenous) interactions. Agents interact directly. The decisions undertaken today by an agent directly depend, through adaptive expectations, on the past choices made by other agents in the population.

6. Bounded rationality. The environment in which real-world economic agents live is too complex for hyper-rationality to be a viable simplifying assumption. It is suggested that one can, at most, impute to agents some local and partial (both in time and space) principles of rationality (e.g., myopic optimization rules). More generally, agents are assumed to behave as boundedly rational entities with adaptive expectations.

7. The nature of learning. Agents in $\mathrm{AB}$ models engage in the open-ended search of dynamically changing environments. This is due to both the ongoing introduction of novelty and the generation of new patterns of behavior; but also on the complexity of the interactions between heterogeneous agents (see point 5 above).

8. "True" dynamics. Partly as a consequence of adaptive expectations (i.e., agents observe the past and form expectations about the future on the basis of the past), AB models are characterized by true, non-reversible, dynamics: the state of the system evolves in a path-dependent manner.

9. Endogenous and persistent novelty. Socio-economic systems are inherently non-stationary. There is the ongoing introduction of novelty in economic systems and the generation of new patterns of behavior, which are themselves a force for learning and adaptation.

10. Selection-based market mechanisms. Agents typically undergo a selection mechanism. For example, the goods and services produced by competing firms are selected by consumers. The selection criteria that are used may themselves be complex and span a number of dimensions.

\subsection{The Basic Structure of ABMs}

Models based on (all or a subset of) the ten main ingredients discussed above typically possess the following structure. There is a population - or a set of populations - of agents (e.g., consumers, firms, etc.), possibly hierarchically organized, whose size may change or not in time. The evolution of the system is observed in discrete time steps, $t=1,2, \ldots$ Time steps may be days, quarters, years, etc.. At each $t$, every agent $i$ is characterized by a finite number of micro-economic variables $\underline{x}_{i, t}$ (which may change across time) and by a vector of micro-economic parameters $\underline{\theta}_{i}$ (that are fixed in the time horizon under study). In turn, the economy may be characterized by some macroeconomic (fixed) parameters $\Theta$.

Given some initial conditions $\underline{x}_{i, 0}$ and a choice for micro and macro parameters, at each time step $t>0$, one or more agents are chosen to update their micro-economic variables. This may happen randomly or can be triggered by the state of the system itself. Agents selected to perform the updating stage collect their available information about the current and past 
state (i.e., micro-economic variables) of a subset of other agents, typically those they directly interact with. They plug their knowledge about their local environment, as well as the (limited) information they can gather about the state of the whole economy, into heuristics, routines, and other algorithmic, not necessarily optimizing, behavioral rules. These rules, as well as interaction patterns, are designed so as to mimic empirical and experimental knowledge that the researcher may have collected from his/her preliminary studies.

After the updating round has taken place, a new set of micro-economic variables is fed into the economy for the next-step iteration: aggregate variables $\underline{X}_{t}$ are computed by simply summing up or averaging individual characteristics. Once again, the definitions of aggregate variables closely follow those of statistical aggregates (i.e., GDP, unemployment, etc.).

The stochastic components possibly present in decision rules, expectations, and interactions will in turn imply that the dynamics of micro and macro variables can be described by some (Markovian) stochastic processes parameterized by micro- and macro-parameters. Hoverer, non-linearities which are typically present in decision rules and interactions make it hard to analytically derive laws of motion, kernel distributions, time- $t$ probability distributions, etc. for the stochastic processes governing the evolution of micro and macro variables.

This suggests that the researcher must often resort to computer simulations in order to analyze the behavior of the ABM at hand. Notice that in some simple cases such systems allow for analytical solutions of some kind. Needless to say, the more one injects into the model assumptions sharing the philosophy of the building blocks discussed above (cf. Section 3.1), the less tractable turns out to be the model, and the more one needs to resort to computer simulations. Simulations must be intended here in a truly constructive way, e.g. to build and "grow" a society "from the bottom up", in the spirit of object-oriented programming.

\subsection{Descriptive Analysis of ABMs}

When studying the outcomes of ABMs, the researcher often faces the problem that the economy he/she is modeling is by definition out-of-equilibrium. The focus is seldom on static equilibria or steady-state paths. Rather, the researcher must more often look for long-run statistical equilibria and/or emergent properties of aggregate dynamics (that is, transient statistical features that last suffficiently long to be observed and considered stable as compared to the time horizon of the model; see Lane, 1993a,b, for an introduction). Such an exploration is by definition very complicated and it is made even more difficult by the fact that the researcher does not even know in advance whether the stochastic process described by its ABM is ergodic or not and, if it somehow converges, how much time will take for the behavior to become sufficiently stable.

Suppose for a moment that the modeler knows (e.g., from a preliminary simulation study or from some ex-ante knowledge coming from the particular structure of the ABM under study) that the dynamic behavior of the system becomes sufficiently stable after some time horizon $T^{*}$ for (almost all) points of the parameter space. Then a possible procedure that can be implemented to study the output of the ABM runs as the one synthetically depicted in Figure 1 .

Given some choice for initial conditions, micro and macro parameters, assume to run our system until it relaxes to some stable behavior (i.e., for at least $T>T^{*}$ time steps). Suppose 


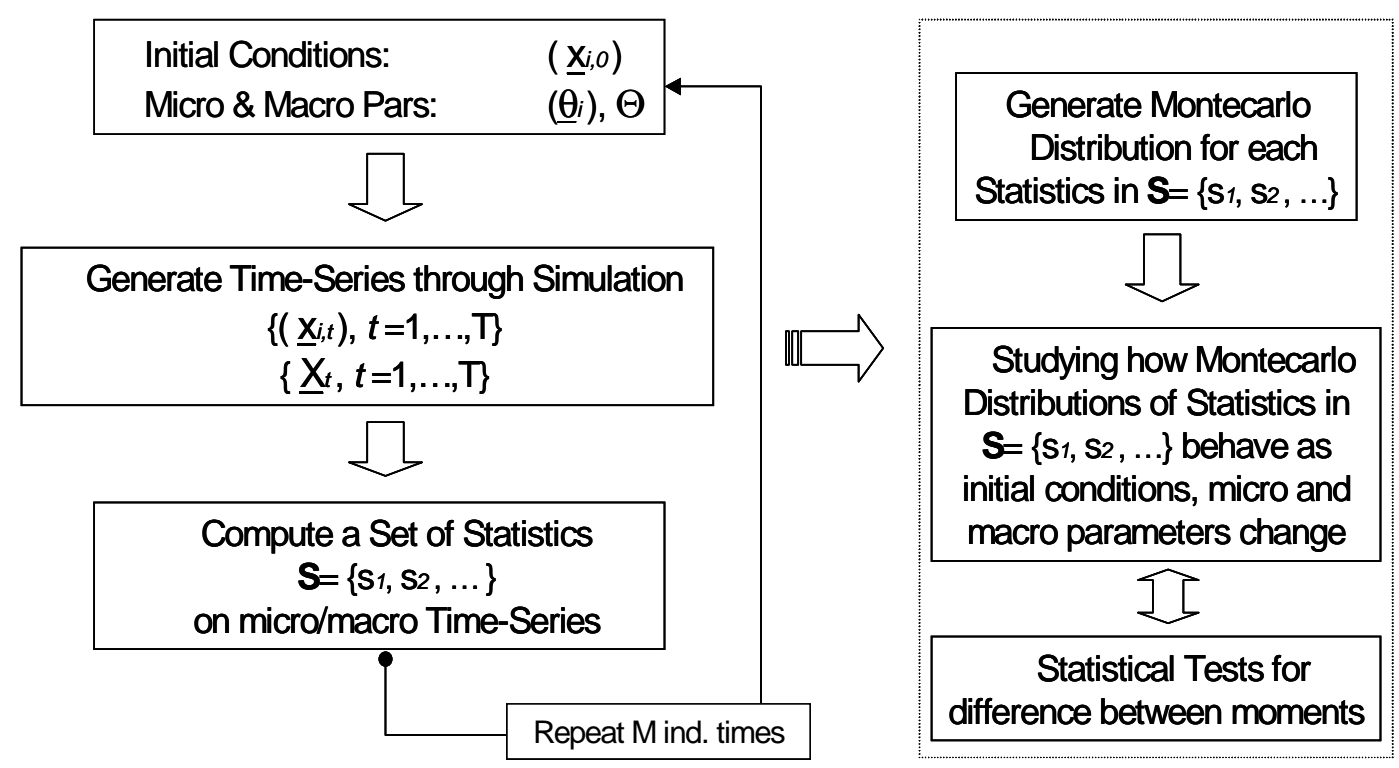

Figure 1: A schematic procedure for studying the output of an $\mathrm{AB}$ model

we are interested in a set $S=\left\{s_{1}, s_{2}, \ldots\right\}$ of statistics to be computed on micro and macro simulated variables. For any given run the program will output a value for each statistic. Given the stochastic nature of the process, each run will output a different value for the statistics. Therefore, after having produced $M$ independent runs, one has a distribution for each statistic containing $M$ observations, which can be summarized by computing its moments.

Recall, however, that moments will depend on the choice made for initial conditions and parameters. By exploring a sufficiently large number of points in the space where initial conditions and parameters are allowed to vary, computing the moments of the statistics of interest at each point, and by assessing how moments do depend on parameters, one might get a quite deep descriptive knowledge of the behavior of the system (see Figure 1).

\subsection{Model Selection and Empirical Validation}

From the foregoing discussion it clearly emerges that in agent-based modeling (as in many other modeling endeavors) one often faces a trade-off between descriptive accuracy and explanatory power of the model. The more one tries to inject into the model "realist" assumptions, the more the system becomes complicated to study and the less clear the causal relations going from assumptions to implications are. ABM researchers are well aware of this problem and have been trying to develop strategies to guide the process of assumption selection. For example, one can try to solve the trade-off between descriptive capability and explanatory power either by beginning with the most simple model and complicate it step-by-step (i.e., the so-called KISS strategy, an acronym standing for "Keep It Simple, Stupid!") or by starting with the most descriptive model and simplify it as much as possible (i.e., the so-called KIDS strategy, "Keep It Descriptive, Stupid!"). A third, alternative strategy prescribes instead to start with an existing 
model and successively complicate it with incremental additions (this strategy might be labeled TAPAS, which stands for "Take A Previous model and Add Something").

In all these procedures, the extent to which the ABM is able to empirically replicate existing reality should play a crucial role in discriminating the point at which any procedure should stop $^{10}$.

Notice that the very structure of ABMs naturally allows one to take the model to the data and validate it against observed real-world observations. Indeed, an ABM model can be thought to provide a family of DGPs, which we think real-world observations being a realization of. More precisely, let us suppose that we believe that observed data are generated by an unknown (to us) colossal DGP, with an almost infinite number of parameters, which we can label as realworld DGP (rwDGP). Suppose further that such rwDGP can be broken in reasonable smaller weakly-exogenous components, each one with a reasonable number of parameters, and each one describing a small set of variables that we are interested in, on the basis of a small set of other variables. Building an ABM means attempting to approximate one of those small rwDGPs. Due to its stochastic structure, an ABM actually mimics the small rwDGP we are studying by a theoretical DGP that generates the same variables each time we run the model. Of course, we only have one observation generated by the rwDGP, and this makes any inference very difficult (but this has to do with another story, which philosophers call the problem of induction...).

Many approaches to empirical validation (and selection) of ABMs can be in principle taken, and the debate is very open here. For example, one might select among ABMs (and within different parameter setups of the same ABM) with respect to the number of stylized facts each of them is able jointly to replicate. A typical procedure to be followed starts with asking whether a particular model can simultaneously reproduce some set of stylized facts for a given parametrization (a sort of "exercise in plausibility"); then explore what happens when the parameter setup changes; finally, investigate if some meaningful causal explanation can be derived out of that step-by-step analysis. Alternatively, one can first select among parameters by calibrating the model (e.g., by directly estimate parameters, when possible, with micro or macro data) and then judge to which extent the calibrated model is able to reproduce the stylized facts of interest.

No matter the empirical validation procedure actually employed, its basic goal is often to restrict the size of the set of free parameters. In fact, over-parameterized models are difficult to interpret and analyze, because no one knows whether the same conclusions could have been obtained in a simpler, less parameterized model. Even if empirical validation allows one to restrict the set of free parameters to a reasonably-sized one, many methodological problems still remain when the model is used to perform policy experiments. If any parametrization represents an alternative world, which one should be employed to assess policy performance? What is the role of initial conditions? We shall briefly go back to these issues in the concluding remarks.

\subsection{Policy Experiments in ABMs: Some Considerations}

ABMs configure themselves as a very powerful device to address policy questions in more realistic, flexible and modular frameworks. Indeed, as far as economic policy is concerned, ABMs

\footnotetext{
${ }^{10}$ For a more in-depth discussion of empirical validation in ABMs, we refer the reader to Fagiolo, Birchenhall, and Windrum (2007) and papers therein.
} 
have many advantages as compared to neoclassical tools as the DSGE model, which we organize in what follows into two classes: theory and empirics.

Theory. ABMs, contrary to neoclassical ones, do not impose any strong theoretical consistency requirements (e.g., equilibrium, representative individual assumptions, rational expectations). This is because they are not required ex-ante to be analytically solvable. Such no-strait-jacket condition allows for an extremely higher flexibility in model building. If this is coupled with a serious empirical-validation requirement (see below), we are in presence of a semi-instrumentalist approach, where bad (but empirically-plausible) assumptions can be replaced with better (and empirically-plausible) ones if the model does not perform as expected. Notice also that in absence of strong consistency conditions, assumptions can be replaced in a modular way, without impairing the analysis of the model. Indeed, in standard neoclassical models one cannot simply replace the optimization assumption with another one just because the model does not behave well, as that would possibly destroy its analytical solvability. This is not so in ABMs: assumptions - or simply small elements of them - can be taken out of the shelf and easily implemented in the model thanks to the flexibility of computer programming languages.

Empirics. As discussed above, ABMs can be thought as generators of alternative worlds, i.e. theoretical DGPs that approximate the unknown one. Contrary to neoclassical models, the structure of ABMs allows more easily to take them to the data. This can be done in two ways. First, one can validate the inputs of ABMs, i.e. fine-tune modeling assumptions about individual behaviors and interactions to make them more similar to the observed ones. Second, one can validate the model on the output side, by e.g. restricting the space of parameters, individual behaviors and interactions, and initial conditions to those that allow the model to replicate the stylized facts of interest. This allows for a degree of realism that is much higher than that exhibited by e.g. DSGE models. Furthermore, thanks to the theoretical flexibility discussed above, the set of stylized facts that one can target can include more than one piece of evidence, as instead happens in neoclassical models. In other words, each neoclassical model is typically build - in order to retain analytical solvability - to explain one or two single stylized facts (see the discussion in Aoki, 2006, for more details). On the contrary, each ABM can easily explain a great deal of pieces of empirical evidence.

But how can one actually conduct policy experiments in ABMs? In a very natural way, indeed. Take again the procedure for ABM descriptive analysis outlined in Figure 1. Recall that micro and macro parameters can be designed in such a way to mimic real-world key policy variables like tax rates, subsidies, interest rates, money, etc. and other key behavioral measures affecting individual incentives in growth, innovation or technologically-related policies. Moreover, initial conditions might play the role of initial endowments and therefore describe different distributional setups. In addition, interaction and behavioral rules employed by economic agents can be easily devised so as to represent alternative institutional, market or industry setup. Since all these elements can be freely interchanged, one can investigate a huge number of alternative policy experiments and rules, the consequences of which can be assessed either qualitatively or quantitatively (e.g., by running standard statistical tests on the distributions of the statistics 
in $S$ ). For example, one might statistically test whether the effect on the moments of the individual consumption distribution (average, etc.) will be changed (and if so by how much) by a percentage change in any given consumption tax rate. Most importantly, all this might be done while preserving the ability of the model to replicate existing stylized facts, e.g. some time-series properties of observed aggregate variables (e.g., persistence of output growth-rate fluctuations) or some relation existing between them (e.g., Phillips curve).

\subsection{Policy in ABMs: A Telegraphic Survey}

The extreme flexibility of ACE modeling has recently motivated researchers to extensively use these approach to address economic policy experiments ${ }^{11}$. A general trend that can be observed is that political decision makers seems more and more willing to believe in findings based on rather detailed simulation models (such as ABMs), where they see a lot of the economic structure they are familiar with ${ }^{12}$, rather than in general insights obtained in quite abstract mathematical models (like the DSGE model).

The number of ABM models that have been recently addressing policy issues is becoming so large that it would be impossible to survey them in a single paper section. We shall therefore outline in a telegraphic way the main fields where these exercises have been performed and briefly discuss some specific examples.

Industrial policy and market design. ABMs offer a unique possibility for evaluating from a comparative perspective alternative policies and institutional changes in rather specific models of particular economic environments, such as particular markets and/or industries, specific auction types, etc.. Indeed, the modeler can tailor his/her ABM so as to precisely mimic a particular instance of the system he/she is interested in, by designing individual behaviors, interaction rules, institutional and technological setups so as to match its empirical or anecdotic knowledge. Examples include detailed models of the U.S. coffee market (Midgley, Marks, and Cooper, 1997) or the pharmaceutical industry (Malerba and Orsenigo, 2002). Along similar lines, Malerba et al. (2008) extend their previous work on "history-friendly" modeling of the evolution of the computer and the semiconductor industry and use the developed simulation model to study the effect of different types of policies (e.g., anti-trust policies, entry-support policies or public procurement on the evolution of industry concentration and the rate of technological change). The emergence of different types of bidding behavior in different market environments is instead the main topic of Duffy and Unver (2008). They simulate the behavior of bidders in two types of auctions - hard or soft close auctions - that differ with respect to the rule governing when the auction is closed. The model is able to reproduce the stylized facts observed in real-world internet auctions and, in addition, offers interesting insights into the features of the bidding functions responsible for the resulting payoffs. The implications for market design are therefore very important ${ }^{13}$. Sun and Tesfatsion (2007) focus instead on the very exciting

\footnotetext{
${ }^{11}$ See for example the papers contained in the special issue "Agent-Based Models for Economic Policy Design" edited by Dawid and Fagiolo (2008).

${ }^{12}$ Moss (2002) discusses the importance of involving the actual decision makers in the process of the generation of agent-based models for policy evaluation.

${ }^{13}$ Ruperez-Micola, Banal-Estanol, and Bunn (2008) consider a stylized model of the value chain in electricity markets and study the problem of the emergence of vertical market power.
} 
and promising area of market design. They report on the development and implementation of an ABM framework (called AMES) for testing the dynamic efficiency and reliability of the Wholesale Power Market Platform (WPMP, i.e. a market design proposed by the U.S. Federal Energy Regulatory Commission for common adoption by all U.S. wholesale power markets). As stated by the authors, AMES "models strategic traders interacting over time in a wholesale power market that is organized in accordance with core WPMP features and that operates over a realistically rendered transmission grid". The usefulness of the AMES framework is illustrated in the paper by presenting a simple static five-node transmission grid test case. AMES provides an exemplar in its detailed specification and the use of open source software that opens up the door for replication and detailed verification by the ABM community.

Fiscal Policy. The assessment of the impact of labor market policies at both the aggregate and individual levels is addressed in Neugart (2008), who develops a multi-sector agent-based model where firms belonging to different sectors require workers with different skills. Using his ABM, Neugart shows that government-financed training measures increase the outflow rate from unemployment, but reduce the outflow rate for those who do not receive subsidies. Therefore, although at the aggregate level the unemployment rate decreases, at the individual level this labor market policy may harm workers who do not receive government transfers ${ }^{14}$. Mannaro, Marchesi, and Setzu (2008) look instead to financial markets and develop an ABM populated by behaviorally-heterogeneous traders with limited resources. They challenge the idea that a Tobin tax is able to stabilize foreign exchange and stock markets, and to reduce speculation. Their simulations show that Tobin-like taxes may actually increase volatility and decrease trading volumes ${ }^{15}$. Russo et al. (2007) develop an ABM where transactions on the good and labor markets take place through bilateral bargaining occurring between heterogenous firms and consumers/workers. Besides reproducing many micro and macro regularities (e.g., sustained growth and fluctuations, Beveridge, Phillips and Okun curves, etc.), they use the model as a computational laboratory and find that aggregate output is non-monotonically linked to the level of tax rate levied on corporate profits if revenues are employed to finance R\&D investment, whereas output is negatively affected if the money collected through taxes is used to provide unemployment benefits.

Growth policy. Dosi, Fagiolo, and Roventini (2008) study a broad set of normative issues regarding the impact of alternative technological and knowledge scenarios on the rates of growth, innovation and imitation of a given country. To do so, they build upon their previous model of endogenous growth and business cycles (Dosi, Fagiolo, and Roventini, 2006) and develop a broader, modular, agent-based framework ${ }^{16}$. They show that this broader model is even able to robustly replicate a higher number of stylized facts than its "ancestor" concerning macroeco-

\footnotetext{
${ }^{14}$ Happe et al. (2008) assess the effect of a regime switch in the way agricultural subsidies are paid on changes in farm structure, prices and farm profits.

${ }^{15}$ Chen and Chie (2008) address the classical question of determining the tax revenue maximizing tax rate in the framework of lottery markets and explain the puzzle why lottery tax rates vary substantially between different countries and lotteries.

${ }^{16}$ In a nutshell, the model describes an economy composed of firms and consumers/workers. Firms belong to two industries. Firms in the first industry perform R\&D and produce heterogeneous machine tools. Firms in the second industry invest in new machines and produce a homogenous consumption good. Consumers sell their labor and consume their income.
} 
nomic dynamics (e.g., cross-correlations, relative volatilities) as well as micro-economic dynamics (e.g., firm size distributions, firm productivity dynamics, firm investment patterns). Furthermore, they define different technological scenarios (e.g., exogenous or endogenous technology frontier, imitation). Finally, they study the long-term impact of a range of different policies considering long-run GDP growth rates, GDP growth-rate volatility and unemployment. Their results show that: (i) patents appear to be detrimental to growth and to increase unemployment; (ii) imitation spurs GDP growth especially in the endogenous technology frontier scenario; (iii) increasing the expected productivity of entrant firms raise GDP long-run growth in the endogenous technology frontier scenario; and (iv) Keynesian demand macro-management policies are a necessary condition for robust GDP growth and reduce business cycle fluctuations. More generally, the results of Dosi, Fagiolo, and Roventini (2008) point to an existing complementarity between Keynesian policies affecting demand and Schumpeterian policies affecting innovation ${ }^{17}$.

Social interactions. Given the importance of direct interaction in ABMs, many authors have explored the impact of alternative network structures and dynamics upon aggregate outcomes. For example, Carayol, Roux, and Yildizoglu (2008) study how properties of networks that emerge due to uncoordinated individual link formation decisions compare to those of efficient networks. Based on their insights policies might be designed with the goal to foster the emergence of efficient networks. Wilhite and Allen (2008) explore the impact of several anti-crime policies dynamically undertaken in societies composed of heterogenous interacting agents. The model is able to explain several real-world patterns concerning the emergence and distribution of crime, and the intertemporal behavior of criminals. For example, larger cities are shown to develop higher crime rates because larger populations increase the incentives to free-ride on public goods. Furthermore, despite crime decreases with protection spending, the impact of prison turn out to be ambiguous, as a higher rate of imprisonment may lead to more crime in the long run.

\section{Concluding Remarks}

The recent debate on the scientific status of economic policy has prompted some authors to conclude that the New Neoclassical Synthesis, armed with its sophisticated modeling tools, is the ultimate and unsurpassable scientific achievement that we can hope for. In this paper, we have tried to argue that the recent relative success of economic policies actually implemented by central banks and other policymakers is not due to the power and sophistication of the underlying theoretical modeling techniques, but rather to a mix of art and experience. Indeed, as discussed in Section 2, DSGE-based models suffer from a series of dramatic problems and difficulties concerning their inner logic consistency, the way they are taken to the data, the extent to which they are able to replicate existing reality, and the realism of their assumptions. These problems are likely to impair any policy exercise that can be devised within their realm. We have also argued that such difficulties are so hard to solve within the neoclassical paradigm that a different research avenue, which attempts to replace the basic pillars of neoclassical economics (rationality, equilibrium, etc.), would be more fruitful.

\footnotetext{
${ }^{17}$ Dawid et al. (2008) study the impact of policies enhancing workers' skills on economic growth and the performance of the labor market.
} 
This alternative paradigm does actually exist and it is called agent-based computational economics (ACE). Section 3 has been devoted to a (necessarily) brief discussion of its philosophical underpinnings, building blocks and policy applications. As our synthetic survey shows, the number of areas where ACE policy experiments have been already applied with success is rather vast and rapidly increasing. The discussion of Section 3 has also outlined the most prominent values added deriving from performing policy experiments within an ACE approach. These include ACE's extreme modeling flexibility; the friendly relation of agent-based models with empirical data; the easiness of carrying out empirical-validation exercises; the almost infinite possibility of experimentation; and, last but not least, the positive impact that a more realistic and algorithmically-structured model can have on political decision makers - as compared to obscure and un-intuitive mathematical neoclassical models.

Of course, as happens for the New Neoclassical Synthesis, many issues are still far from being settled and the debate is very open. Here, by a way of conclusion, we recall just three of them.

The first issue - which we can label as the problem of over-parametrization - has to do with the role played by micro and macro parameters in ABMs. As mentioned, ABMs are often over-parameterized, for one typically injects in the specification of agents' behavioral rules and interaction patterns many ingredients in order to meet as much as possible what he/she observes in reality. Suppose for simplicity that initial conditions do not matter. Even if empirical validation can provide a way to reduce free parameters, the researchers are almost always left with an ABM whose behavior depends on many free parameters. Many questions naturally arise. How can one interpret these different parameterizations? Which one should be used if one employs the model to deliver policy implications? Should one perfectly calibrate (if possible) the model using the data so that no free parameters are left? Should policy implications be robust to alternative parameterizations instead? Notice that this issue is closely related to a common critique that ABMs usually face: if an ABM contains many free parameters and it is able to reproduce a given set of stylized facts, how can one be sure that it represents the minimal mechanisms capable of reproducing the same set of stylized facts? This point reminds the "unconditional objects" critique in Brock (1999) and it is certainly true for "oversized" ABMs. In practice, however, ACE researchers are well aware of the problem and always try to simplify as much as possible their model by using empirical validation techniques and a KISS or TAPAS approach. Even if it is very difficult to show that a given ABM is the minimal model describing a set of stylized facts, the more stylized facts a model can reproduce, the more one is able to restrict the class of theoretical mechanisms that can do the job.

The second issue concerns the role played by initial conditions. Recall that (if random ingredients are present in the model) any ABM can be considered as an artificial (stochastic) data generation process $(m D G P)$ with which we try to approximate the one that generated the data that we observe (i.e., the $r w D G P$ ). The question is: is the rwDGP ergodic or not? If the underlying real-world $r w D G P$ is thought to be non-ergodic (as well as the theoretical $m D G P$ described in the $\mathrm{AB}$ model), then initial conditions matter. This raises a whole host of problems for the modeler. The modeler needs to identify the "true" set of initial conditions in the empirical data, generated by the $r w D G P$, in order to correctly set the initial parameters of the model. Even if the "perfect database" would exist, this is a very difficult task. How far in 
the past does one need to go in order to identify the correct set of initial values for the relevant micro and macro variables? There is a possibility of infinite regress. If this is the case, then one may need data stretching back a very long time, possibly before data started to be collected.

This issue is closely related to a third (and final) one, regarding the relation between simulated and real-world data. While in principle we could generate as many theoretical observations as we like, in practice we may only have a few of such empirical realizations (possibly only one!). If we believe that the empirical observations come from an underlying DGP that could have been "played twice" (i.e., could have generated alternative observations, other than the one we have) the problem of comparing simulated with empirical data becomes very complicated.

It must be said that all three issues above are the subject of never-ending debates among philosophers of science, since they raise fundamental questions related to probability, modeling, inference, etc. (see, e.g., Fagiolo, Moneta, and Windrum, 2007). As such, they might (and do) affect any stochastic, dynamic (economic) model, DSGE-based ones included. Nevertheless, the large majority of those advocating the New Neoclassical Synthesis approach seems not to care about them. In our view, the fact that they instead occupy center stage in the current ACE debate is another signal of the vitality of this young but promising paradigm.

\section{References}

Aghion, P. and P. Howitt (2007), "Appropriate Growth Policy: A Unifying Framework", Journal of the European Economic Association, 4: 269-314.

Akerlof, G. A. (2007), "The Missing Motivation in Macroeconomics", American Economic Review, 97: 5-36.

Albert, R. and A. L. Barabasi (2002), "Statistical Mechanics of Complex Networks", Rev. Mod. Phys., 4: 47-97.

Alessi, L., M. Barigozzi and M. Capasso (2007), "A Review of Nonfundamentalness and Identification in Structural VAR models", Working Paper 2007/22, Laboratory of Economics and Management (LEM).

Aoki, M. (2006), "Not More So: Some Concepts Outside the DSGE Framework", in Colander, D. (ed.), PostWalrasian Macroeconomics. Cambdridge, Cambdridge University Press.

Benhabib, J., S. Schmitt-Grohé and M. Uribe (2001), "The Perils of Taylor Rules", Journal of Economic Theory, 96: $40-69$.

Beyer, A. and R. E. A. Farmer (2004), "On the Indeterminacy of New-Keynesian Economics", Working Paper 323, ECB.

Brock, W. A. (1999), "Scaling in Economics: A Reader's Guide", Industrial and Corporate Change, 8: 409-46.

Brock, W. A., S. Durlauf, J. M. Nason and G. Rondina (2007), "Simple Versus Optimal Rules as Guides to Policy", Journal of Monetary Economics, 54: 1372-1396.

Brock, W. A. and S. N. Durlauf (2001), "Interactions-Based Models", in Heckman, J. and E. Leamer (eds.), Handbook of Econometrics, Vol. 5. Amsterdam, North Holland.

Calvo, G. A. (1983), "Staggered Prices in a Utility-Maximizing Framework", Journal of Monetary Economics, 12: $383-398$.

Canova, F. (2007), "How Much Structure in Empirical Models?", in Mills, T. and K. Patterson (eds.), Palgrave Handbook of Economics, Vol. 2, Applied Econometrics.

Canova, F. and L. Sala (2005), "Back to Square One: Identification Issues in DSGE Models", Working Paper 583 , ECB. 
Carayol, N., P. Roux and M. Yildizoglu (2008), "Inefficiencies in a Model of Spatial Networks Formation with Positive Externalities", Journal of Economic Behavior and Organization, Special Issue on "Agent-Based Models for Economic Policy Design", edited by Dawid, H. and Fagiolo, G., forthcoming.

Chen, S.-H. and B.-T. Chie (2008), "Lottery Markets Design, Micro Structure and Macro Behavior: An ACE Approach", Journal of Economic Behavior and Organization, Special Issue on "Agent-Based Models for Economic Policy Design", edited by Dawid, H. and Fagiolo, G., forthcoming.

Christiano, L. G., M. Eichenbaum and C. L. Evans (2005), "Nominal Rigidities and the Dynamic Effects of a Shock to Monetary Policy", Journal of Political Economy, 113: 1-45.

Clarida, R., J. Galí and M. Gertler (1999), "The Science of Monetary Policy: A New Keynesian Perspective", Journal of Economic Literature, 37: 1661-1707.

Cogley, T. and J. M. Nason (1993), "Impulse Dynamics and Propagation Mechanisms in a Real Business Cycle Model", Economic Letters, 43: 77-81.

Colander, D. (2005), "The Future of Economics: the Appropriately Educated in Pursuit of the Knowable", Cambridge Journal of Economics, 29: 927-941.

Dawid, H. and G. Fagiolo (eds.) (2008), Special Issue on "Agent-Based Models for Economic Policy Design". In Journal of Economic Behavior and Organization, forthcoming.

Dawid, H., S. Gemkow, P. Harting, K. Kabus and K. Neugart, M.and Wersching (2008), "Skills, Innovation, and Growth: An Agent-Based Policy Analysis", Working paper, Bielefeld University.

Debreu, G. (1974), "Excess Demand Function”, Journal of Mathematical Economics, 1: 15-23.

Dixit, A. and J. Stiglitz (1977), "Monopolistic Competition and Optimum Product Diversity", American Economic Review, 67: 297-308

Dosi, G., G. Fagiolo and A. Roventini (2006), "An Evolutionary Model of Endogenous Business Cycles", Computational Economics, 27: 3-34.

Dosi, G., G. Fagiolo and A. Roventini (2008), "Patterns of Innovation and the Political Economy of Growth. An Exploration of Different Policy Regimes", Working paper, Laboratory of Economics and Management (LEM), forthcoming.

Duffy, J. and M. Unver (2008), "Internet Auctions with Artificial Adaptive Agents: A Study on Market Design", Journal of Economic Behavior and Organization, Special Issue on "Agent-Based Models for Economic Policy Design", edited by Dawid, H. and Fagiolo, G., forthcoming.

Fagiolo, G., C. Birchenhall and P. Windrum (eds.) (2007), Special Issue on "Empirical Validation in Agent-Based Models". In Computational Economics, Volume No. 30, Issue No. 3.

Fagiolo, G., A. Moneta and P. Windrum (2007), "A Critical Guide to Empirical Validation of Agent-Based Models in Economics: Methodologies, Procedures, and Open Problems", Computational Economics, 30: 195-226.

Fagiolo, G., M. Napoletano and A. Roventini (2007), "Are Output Growth-Rate Distributions Fat-Tailed? Some Evidence from OECD Countries", Journal of Applied Econometrics, forthcoming.

Favero, C. (2007), "Model Evaluation in Macroeconometrics: From Early Empirical Macroeconomic Models to DSGE Models", Working Paper 327, IGIER.

Fernandez-Villaverde, J., J. F. Rubio-Ramirez and T. Sargent (2005), “A, B, C's, (and D's) for Understanding VARs", Technical Working Paper 308, NBER.

Forni, M. and M. Lippi (1997), Aggregation and the Microfoundations of Dynamic Macroeconomics. Oxford, Oxford University Press.

Forni, M. and M. Lippi (1999), "Aggregation of Linear Dynamic Microeconomic Models", Journal of Mathematical Economics, 31: 131-158.

Friedman, M. (1953), "The Methodology of Positive Economics", in Friedman, M. (ed.), Essays in Positive Economics. Chicago, University of Chicago Press.

Fukac, M. and A. Pagan (2006), "Issues in Adopting DSGE Models for Use in the Policy Process", Working Paper 10/2006, CAMA. 
Fukuyama, F. (1992), The End of History and the Last Man. London, Penguin.

Galí, J. (2007), Monetary Policy, Inflation, and the Business Cycle. Unpublished manuscript.

Galí, J. and M. Gertler (2007), "Macroeconomic Modelling for Monetary Policy Evaluation", Journal of Economic Perspectives, forthcoming.

Giannoni, M. P. and M. Woodford (2002a), "Optimal Interest-Rate Rules: I. General Theory", Working Paper 9419, NBER.

Giannoni, M. P. and M. Woodford (2002b), "Optimal Interest-Rate Rules: II. Applications", Working Paper 9420, NBER.

Goodfriend, M. (2007), "How the World Achieved Consensus on Monetary Policy", Journal of Economic Perspectives, 21: 47-68.

Goodfriend, M. and R. King (1997), "The New Neoclassical Synthesis and the Role of Monetary Policy", NBER Macroeconomics Annual, pp. 231-282.

Happe, K., A. Balmann, K. Kellermann and C. Sahrbacher (2008), "Does Structure Matter? The Impact of Switching the Agricultural Policy Regime on Farm Structures", Journal of Economic Behavior and Organization, Special Issue on "Agent-Based Models for Economic Policy Design", edited by Dawid, H. and Fagiolo, G., forthcoming.

Juselius, K. and M. Franchi (2007), "Taking a DSGE Model to the Data Meaningfully", Economics Discussion Papers 2007-6, Kiel Institute for the World Economy.

Kahneman, D. and A. Tversky (eds.) (2000), Choices, Values, and Frames. Cambridge MA, Cambridge University Press.

King, R. and S. Rebelo (1999), "Resuscitating Real Business Cycles", in Taylor, J. and M. Woodford (eds.), Handbook of Macroeoconomics. Elsevier Science: Amsterdam.

Kirman, A. P. (1989), "The Intrinsic Limits of Modern Economic Theory: the Emperor Has no Clothes", Economic Journal, 99: 126-39.

Kirman, A. P. (1992), "Whom or What Does the Representative Individual Represent?", Journal of Economic Perspectives, 6: 117-136.

Kirman, A. P. and K. Koch (1986), "Market Excess Demand Functions: Identical Preferences and Collinear Endowments", Review of Economic Studies, 53: 457-463.

Lane, D. A. (1993a), "Artificial Worlds and Economics, Part I", Journal of Evolutionary Economics, 3: 89-107.

Lane, D. A. (1993b), "Artificial Worlds and Economics, Part II", Journal of Evolutionary Economics, 3: $177-97$.

Lindley, D. (1994), The End of Physics. Basic Books.

Malerba, F., R. Nelson, L. Orsenigo and S. Winter (2008), "Public Policies and Changing Boundaries of Firms in a History-Friendly Model of the Co-evolution of the Computer and Semiconductor Industries", Journal of Economic Behavior and Organization, Special Issue on "Agent-Based Models for Economic Policy Design", edited by Dawid, H. and Fagiolo, G., forthcoming.

Malerba, F. and L. Orsenigo (2002), "Innovation and Market Structure in the Dynamics of the Pharmaceutical Industry and Biotechnology: Towards a History-Friendly Model", Industrial and Corporate Change, 11: 667703 .

Mankiw, G. N. and D. Romer (eds.) (1991), New Keynesian Economics, Cambridge MA, MIT Press.

Mannaro, K., M. Marchesi and A. Setzu (2008), "Using an Artificial Financial Market for Assessing the Impact of Tobin-like Transaction Taxes", Journal of Economic Behavior and Organization, Special Issue on "Agent-Based Models for Economic Policy Design", edited by Dawid, H. and Fagiolo, G., forthcoming.

Mantel, R. (1974), "On the Characterization of Aggregate Excess Demand", Journal of Economic Theory, 7: $348-353$.

Midgley, D., R. Marks and L. Cooper (1997), "Breeding Competitive Strategies", Management Science, 43: 257275 . 
Mishkin, F. S. (2007), "Will Monetary Policy Become More of a Science", Working Paper 13566, NBER.

Neugart, M. (2008), "Labor Market Policy Evaluation with ACE", Journal of Economic Behavior and Organization, Special Issue on "Agent-Based Models for Economic Policy Design", edited by Dawid, H. and Fagiolo, G., forthcoming.

Pyka, A. and G. Fagiolo (2007), "Agent-Based Modelling: A Methodology for Neo-Schumpeterian Economics", in Hanusch, H. and A. Pyka (eds.), The Elgar Companion to Neo-Schumpeterian Economics. Cheltenham, Edward Elgar Publishers.

Ravenna, F. (2007), "Vector Autoregressions and Reduced Form Representations of DSGE Models", Journal of Monetary Economics, 54: 2048-2064.

Rotemberg, J. and M. Woodford (1999), "Interest Rate Rules in an Estimated Sticky Price Model", in Taylor, J. (ed.), Monetary Policy Rules. University of Chicago Press: Chicago.

Ruperez-Micola, A., A. Banal-Estanol and D. Bunn (2008), "Incentives and Coordination in Vertically Related Energy Markets", Journal of Economic Behavior and Organization, Special Issue on "Agent-Based Models for Economic Policy Design", edited by Dawid, H. and Fagiolo, G., forthcoming.

Russo, A., M. Catalano, M. Gallegati, E. Gaffeo and M. Napoletano (2007), "Industrial Dynamics, Fiscal Policy and R\&D: Evidence from a Computational Experiment", Journal of Economic Behavior and Organization, 64: $426-447$.

Schmitt-Grohé, S. and M. Uribe (2000), "Price Level Determinacy and Monetary Policy under a Balanced-Budget Requirement", Journal of Monetary Economics, 45: 211-246.

Smets, F. and R. Wouters (2003), "An Estimated Dynamic Stochastic General Equilibrium Model of the Euro Area", Journal of the European Economic Association, 1: 1123-1175.

Sonnenschein, H. (1972), "Market Excess Demand Functions", Econometrica, 40: 549-556.

Sun, J. and L. Tesfatsion (2007), "Dynamic Testing of Wholesale Power Market Designs: An Open-Source AgentBased Framework", Computational Economics, 30.

Taylor, J. (1993), "Discretion versus Policy Rules in Practice", Carnegie-Rochester Series on Public Policy, 39 : 195-214.

Taylor, J. (2007), "The Explanatory Power of Monetary Policy Rules", Working Paper 13685, NBER.

Tesfatsion, L. (2006), "ACE: A Constructive Approach to Economic Theory", in Tesfatsion, L. and K. Judd (eds.), Handbook of Computational Economics II: Agent-Based Computational Economics. North Holland, Amsterdam.

Tesfatsion, L. and K. Judd (eds.) (2006), Handbook of Computational Economics II: Agent-Based Computational Economics. North Holland, Amsterdam.

Wilhite, A. and W. Allen (2008), "Crime, Protection, and Incarceration", Journal of Economic Behavior and Organization, Special Issue on "Agent-Based Models for Economic Policy Design", edited by Dawid, H. and Fagiolo, G., forthcoming.

Woodford, M. (2003), Interest and Prices: Foundations of a Theory of Monetary Policy. Princeton, NJ, Princeton University Press.

Zarnowitz, V. (1985), "Recent Works on Business Cycles in Historical Perspectives: A Review of Theories and Evidence", Journal of Economic Literature, 23: 523-80.

Zarnowitz, V. (1997), "Business Cycles Observed and Assessed: Why and How They Matter", Working Paper 6230, NBER. 